\title{
Nace TEMPORÁNEA, nueva revista de acceso abierto sobre la historia de la arquitectura
}

Tendrá una periodicidad anual. Y en marzo 2020 ha salido el primer número. TEMPORÁNEA. Revista de Historia de la Arquitectura, vinculada a la Universidad de Sevilla, va dirigida preferentemente a la comunidad científica y universitaria dedicada a la investigación en Historia de la Arquitectura. Es un título más de acceso abierto que se suma al amplio conjunto de publicaciones editadas con la plataforma libre Open Journal Systems. De carácter internacional, desde este número inaugural abarca ya diversos períodos históricos y ámbitos geográficos.

Mar Loren-Méndez | Dpto. de Historia, Teoría y Composición Arquitectónicas, Universidad de Sevilla

Url de la contribución <www.iaph.es/revistaph/index.php/revistaph/article/view/4642>

TEMPORÁNEA. Revista de Historia de la Arquitectura construye un foro internacional en el campo de la Historia de la Arquitectura, desde cualquier disciplina, período cronológico y ámbito geográfico, y promueve la diversidad y complejidad de la historia como valores irrenunciables. Junto con esta aproximación transversal y plural, esta publicación defiende el carácter multiescalar de la arquitectura abarcando la historia del objeto construido, la ciudad y el territorio. Colmando el vacío existente de publicaciones especializadas en esta materia en España, la revista tiene un marcado carácter internacional, que se traduce en la participación activa de expertos internacionales tanto en sus órganos como en las investigaciones que en ella se publican, aceptando textos en castellano, inglés, francés, italiano, portugués y alemán.

Se trata de una revista científica del sello editorial de la Universidad de Sevilla EUS, editorial española de impacto con más sellos de calidad en edición académica y perteneciente al Sistema EFQM de calidad y excelencia. TEMPORÁNEA va dirigida preferentemente a la comunidad científica y universitaria dedicada a la investigación en Historia de la Arquitectura. Con una periodicidad anual, publica artículos científicos seleccionados por el sistema de evaluación de pares dobles ciegos y a través de un proceso editorial caracterizado por la calidad, el rigor y la transparencia, por el que vela un comité editorial con un marcado carácter internacional.
TEMPORÁNEA ha publicado su número inaugural en marzo de 2020 y mantiene siempre abierta la recepción de artículos de las temáticas de interés de la revista. En su sección atemporánea la revista publica artículos de investigación de cualquier período histórico y de cualquier parte del mundo, complementados con textos breves de su sección contemporánea, que incluye recensiones de libros o reseñas de exposiciones, actividades y en general temas de actualidad para la historia de la arquitectura. La sección de temática monográfica extemporánea aparece de manera eventual en determinados números de la revista.

TEMPORÁNEA participa de la edición en acceso abierto que promueve la Universidad de Sevilla a través del portal informático de la EUS, velando por la máxima difusión e impacto y por la transmisión del conocimiento científico de calidad y riguroso. Se compromete así con la comunidad académica en garantizar la ética y calidad de los artículos publicados, tomando como referencia el Código de Conducta y Buenas Prácticas para editores de revistas científicas que define el Comité de Ética de Publicaciones (COPE). Todas las partes implicadas en el proceso de edición se comprometen a conocer y acatar los principios de este código.

Más información:

https://revistascientificas.us.es/index.php/TEMPORANEA/ index 